\title{
Safety and Metabolism of AOD9604, a Novel Nutraceutical Ingredient for Improved Metabolic Health
}

\author{
Margret I. Moréa, c, David Kenley ${ }^{\mathrm{b}}$
}

\begin{abstract}
Background: AOD9604 is the C-terminal fragment (TyrhGH177-191) of human growth hormone (hGH). Early stage studies with AOD9604 have shown positive activities on fat metabolism. As a result the use of AOD9604 to improve metabolic profiles may be plausible. For these uses, the safety of AOD9604 needs to be clearly demonstrated. Here we report the findings from studies involving the genotoxicological, toxicological and pharmacokinetic testing of AOD9604.
\end{abstract}

Methods: In an Ames test, the mutagenic potential of AOD9604 was assessed. A chromosomal aberration assay in CHO cells was used to test the mutagenic activity of AOD9604 by its ability to cause structural damage to chromosomes. A bone micronucleus assay incorporated in a 4-week rat intravenous (IV) toxicity study was used to test potential micronucleus formation. In chronic toxicology studies in rats ( 6 months) and cynomolgus monkeys ( 9 months), the potential toxicity of AOD9604 was assessed after daily oral gavage. Pharmacokinetic properties of AOD9604 were examined in a study with pigs after oral and IV administration, and rat whole-body radiography after IV and oral ${ }^{14} \mathrm{C}$-AOD9604 application.

Results: AOD9604 was found to be generally safe after chronic oral application in rats and cynomolgus monkeys. There was no evidence of any genotoxic activities of AOD9604, as examined in an Ames test, a chromosomal aberration assay, or a bone micronucleus assay. Rat whole-body radiography revealed similar organ distribution after IV or oral application. Orally administered AOD9604 in pigs was well absorbed and results revealed rapid degradation kinetics.

Conclusion: Multiple non-clinical studies revealed no evidence of

\footnotetext{
Manuscript accepted for publication April 25, 2014

a analyze \& realize GmbH, Waldseeweg 6, 13467 Berlin, Germany

${ }^{\mathrm{b}}$ Metabolic Pharmaceuticals Pty Ltd, Unit 2, 320 Lorimer St, Port Melbourne, VIC 3207, Australia

${ }^{\mathrm{c} C o r r e s p o n d i n g ~ a u t h o r: ~ M a r g r e t ~ I . ~ M o r e ́, ~ a n a l y z e ~ \& ~ r e a l i z e ~} \mathrm{GmbH}$, Waldseeweg 6, 13467 Berlin, Germany. Email: mmore@a-r.com

doi: http://dx.doi.org/10.14740/jem213w
}

genotoxicological or toxicological concerns regarding the safety of AOD9604.

Keywords: AOD9604; hGH; C-terminus of human growth hormone; Non-clinical studies; Pharmacokinetics; Toxicology; Metabolism; Obesity

\section{Introduction}

Obesity, and its correlated metabolic and physiological problems including type 2 diabetes, cardiovascular disease and osteoarthritis, is one of the leading causes of a severely reduced quality of life and a shortened lifespan [1].

AOD9604, the C-terminal fragment of the human growth hormone (hGH) (Tyr-hGH177-191), was initially developed as an obesity treatment. Prepared by solid phase peptide synthesis, it contains an additional tyrosine at the Nterminal end for peptide stabilization and is cyclized by disulphide bonding between the two cysteine residues. The 3D structure of AOD9604 is similar to the homologous region of complete hGH [2].

The rationale for using a $\mathrm{C}$-terminal fragment of $\mathrm{hGH}$ lies in its physiological function, including stimulation of lipolysis in adipocytes. In obese humans, growth hormone secretion is profoundly, but reversibly, suppressed [3].

The hGH is a single-chain $22 \mathrm{kDa}, 191$ amino acid polypeptide, with different isoforms being present in blood plasma [4]. The hGH can be growth-promoting in almost every tissue [5-7].

In adults, various metabolic functions are known. For example, in the liver, hGH induces insulin-like growth factor-1 (IGF-1) and many of the in vivo effects of hGH are ascribed to this IGF-1 secretion. The significant role of hGH in the regulation of carbohydrate and lipid metabolism is well documented [8-10]. Interestingly, in adipose tissue hGH can induce inhibition of lipoprotein lipase activity, thus stimulating lipolysis and resulting in a reduction of fat cell mass [11-14].

Accordingly, systemic hGH treatment in rodents and humans influences fat distribution, particularly abdominal fat, 
Table 1. Overview of Studies Contained in This Report

\begin{tabular}{|c|c|c|c|c|c|}
\hline Study type & Year & Species & $\begin{array}{l}\text { Mode of } \\
\text { Administration }\end{array}$ & $\begin{array}{l}\text { (Run-in Phase) } \\
\text { Study duration }\end{array}$ & Brief outcome summary \\
\hline $\begin{array}{l}\text { Genotoxicity - Ames } \\
\text { test }\end{array}$ & 1999 & $\begin{array}{l}\text { S. typhimurium } \\
\text { E. coli }\end{array}$ & in vitro & ca. 2 weeks & $\begin{array}{l}\text { No genotoxicological } \\
\text { concerns }\end{array}$ \\
\hline $\begin{array}{l}\text { Genotoxicity - } \\
\text { chromosomal } \\
\text { aberration assay }\end{array}$ & 1999 & $\mathrm{CHO}$ cells & in vitro & ca. 3 weeks & $\begin{array}{l}\text { No clastogenic activity, } \\
\text { inconsistent evidence of } \\
\text { interfering with cell cycling }\end{array}$ \\
\hline $\begin{array}{l}\text { Toxicology and } \\
\text { Genotoxicity - bone } \\
\text { marrow micronucleus }\end{array}$ & 2002 & Rat & IV & $\begin{array}{l}\text { ( } 15 \text { days) } \\
28 \text { days repeated } \\
\text { dose }\end{array}$ & $\begin{array}{l}\text { No genotoxicological } \\
\text { concerns, reduced body } \\
\text { mass gain }\end{array}$ \\
\hline $\begin{array}{l}{ }^{14} \mathrm{C}-\mathrm{AOD} 9604: \\
\text { Quantitative whole- } \\
\text { body radiography }\end{array}$ & 2004 & Rat & in vitro, IV or oral & 1 day; 1 day & $\begin{array}{l}\text { Label of various tissues } \\
\text { and organs after IV or oral } \\
\text { administration }\end{array}$ \\
\hline Pharmacokinetics & 2000 & Pig & $\begin{array}{l}\text { IV and oral with } \\
\text { food }\end{array}$ & $\begin{array}{l}(2 \text { weeks }) \\
3 \text { days of dosing }\end{array}$ & $\begin{array}{l}\text { IV: rapid plasma clearance } \\
\text { oral: slower kinetics }\end{array}$ \\
\hline Toxicology & 2006 & Rat & Oral gavage & $\begin{array}{l}\text { (11 days) } \\
6 \text { months repeated } \\
\text { dose }\end{array}$ & No toxicological concerns \\
\hline Toxicology & 2004 & $\begin{array}{l}\text { Cynomolgus } \\
\text { monkey }\end{array}$ & Oral gavage & $\begin{array}{l}(5-11 \text { weeks }) \\
9 \text { months } \\
\text { repeated dose }\end{array}$ & No toxicological concerns \\
\hline
\end{tabular}

and reduces body fat mass [15-20]. However side effects can include glucose intolerance, diabetes and insulin resistance, acromegaly, cancer, edema and hypertension [4, 16, 21-24].

A $20 \mathrm{kDa}$ alternatively spliced form of the hGH was recently clinically considered due to reduced diabetogenicity [25]. However in a clinical setting, glucose tolerance was slightly impaired and peripheral edema was observed [26].

Specific domains of hGH can be assigned to different functions: for instance the amino terminal region exhibits an insulin-potentiating action [27-29], while amino acids 108 129 of hGH were found to evoke high mitogenic responses [30].

Interestingly, the carboxyl terminus (amino acids 177 191) appears to be a lipid mobilizing domain with inhibitory action on the acetyl-CoA carboxylase activity in hepatocytes and adipocytes [31]. Several C-terminal fragments were synthesized and tested for their effects in a number of animal models of obesity.

Early studies using genetically obese rats and mice showed the fragment hGH 177 - 191 to stimulate lipolysis and inhibit lipogenesis [32-35]. AOD9604 showed metabolic effects similar to those of intact hGH, with respect to energy balance and fat oxidation in chronically treated animals [36]. AOD9604 elicited the fat reducing effect without inducing insulin resistance [31]. AOD9604 did not stimulate the production of IGF-1 in any of the systems studied.

The mechanism of action of AOD9604 is not understood, although it clearly shares some of the biological effects of hGH, for example, on adipose tissues, but not others, for example, IGF-1 production. Ligand binding experiments indicate that AOD9604 is not a high affinity antagonist of hGH binding to the GH receptor [36]. A study using obese mice revealed that AOD9604 may partially function by increasing the repressed levels of beta-3-adrenoreceptor RNA expression [37].

Recently, AOD9604 received "generally recognized as safe" (GRAS) status, conditional on publication of pre-existing safety data, for its intended use in foods, drinks and dietary supplements.

Six human clinical trials have been performed with AOD9604, including two intravenous (IV) and two oral dosing pilot studies. Two oral phase IIb studies with 300 and 500 obese adults were performed to assess efficacy (body mass reduction), safety and tolerability. In all human studies, 
AOD9604 was found to be safe and well tolerated [38]. Effects of AOD9604 on weight loss were seen in initial trials but were not seen in the last study in which an intensive diet and exercise regime was incorporated. The weight loss when observed in earlier trials, was similar in extent and location to that observed with hGH in published studies, and supports steady, moderate weight reduction, with effects particularly on abdominal fat (manuscript in preparation).

Prior to the clinical trials, toxicological and pharmacokinetic animal experiments were performed, including genotoxicological studies to exclude mutagenic or clastogenic activities (Table 1). The objective of this original research paper is to summarize and discuss the safety data obtained from these non-clinical trials. All of the non-clinical studies reported in this paper were sponsored by Metabolic Pharmaceuticals Limited.

\section{Materials and Methods}

The in vitro studies were conducted in accordance with GLP standards. The animal studies were approved by a local ethics committee and conducted in accordance with GLP standards, as well as the UK Animals Act 1986.

\section{Bacterial reverse mutation test (Ames test)}

This study was conducted by Quintiles Toxicology/Pathology Services - Quintiles England Limited, Ledbury, UK, report dated September 1999. AOD9604 was tested for its ability to induce mutations in four histidine dependent auxotrophic mutants of Salmonella typhimurium (strains TA1535, TA1537, TA98 and TA100) and one tryptophan dependent auxotrophic mutant of Escherichia coli (strain WP2 uvrA).

Plate incorporation and pre-incubation methods were used by applying dimethylsulphoxide-dissolved AOD9604 in the absence or presence of the standard metabolic activation system S-9. Plate incorporation doses were $0,1.6,8$, 40, 200, 1,000 and 2,000 $\mu \mathrm{g}$ AOD9604/plate; pre-incubation doses were: $0,8,40,200,1,000$ and 2,000 $\mu \mathrm{g} /$ plate, and as a repeat (WP2uvrA with S-9) 0, 50, 300, 500, 800 and 1,000 $\mu \mathrm{g} / \mathrm{plate}$.

\section{In vitro chromosome aberration assay}

This study was supervised by Quintiles Toxicology/Pathology Services - Quintiles England Limited, Ledbury, UK, report dated December 1999. In two experiments, Chinese Hamster Ovary (CHO) cells (standard culture conditions), were treated with AOD9604 in the absence or presence of S-9. For the first experiment 20, 50, 100 and $200 \mu \mathrm{g} / \mathrm{mL}$ (precipitating dose) AOD9604 were applied for $3 \mathrm{~h}$, with harvesting approximately 1.5 cell cycles after dosing. In the second experiment, treatment was for $3 \mathrm{~h}$ in the presence of S-9 and 1.5 cell cycles in the absence of S-9, with 2 harvest times at 1.5 cell cycles and $24 \mathrm{~h}$ later. In the absence of S-9 treatment 500 and $1,000 \mu \mathrm{g} / \mathrm{mL}$ AOD9604 were used as additional concentrations. Three separate positive controls used mitomycin-C (without S-9), cyclophosphamide and benzo(a)pyrene (S-9).

Cytotoxicity was determined by counting colony forming capacity of the treated cells. Additionally, CHO-cell chromosomes were arrested in metaphase (addition of 0.36 $\mu \mathrm{g} / \mathrm{mL}$ colcemid $2 \mathrm{~h}$ before harvest), swollen in $0.075 \mathrm{M} 37$ ${ }^{\circ} \mathrm{C} \mathrm{KCl}$ solution (5 min), fixed in ethanol/glacial acetic acid $(3 / 1, v / v)$, and examined microscopically after staining with 5\% (v/v) Gurrs Giemsa R66. Mounted slides were coded to mask dose related information during slide scoring.

\section{Four-week IV toxicity study in rats incorporating micro- nucleus test}

This study was performed by Huntingdon Life Sciences Ltd, Huntingdon, UK, report dated July 2002. For 15 days, Sprague-Dawley rats were acclimatized to standard rodent facility conditions, with 3 - 5 rats of the same sex per cage. Rats had access to tap water and pelleted SDS Rat and Mouse No. 1 SQC modified maintenance diet (Special Diets Service, UK), except overnight (ca. $16 \mathrm{~h}$ ) before urine and blood collection. The animals, aged 7 - 8 weeks $(211$ - $272 \mathrm{~g}$ males; 165 - $201 \mathrm{~g}$ females) were divided into three groups of ten male and ten female rats. Prior to the commencement of the study the proposed formulation procedure was checked by chemical analysis to confirm that the method was acceptable, homogeneity and stability of the formulation was satisfactory under the conditions of the study and there were no losses of test substance through the dosing equipment. The animals received IV 0.1, 1.0 or $10 \mathrm{mg} / \mathrm{kg}$ AOD $9604 /$ day (same time each day) to the caudal vein for 4 weeks, preceded and followed by a $0.5 \mathrm{~mL}$ physiological saline flush. As control, five male and five female animals received vehicle (L-glutamic acid/D-mannitol buffer) alone. The dosing volume was $2 \mathrm{mg} / \mathrm{kg}$. As positive control for the micronucleus test five males and five females received a single dose of 10 $\mathrm{mg} / \mathrm{kg}$ cyclophosphamidine.

During the study, clinical signs were observed daily, and body masses were recorded twice a week. At weekly intervals, animals were examined physically in detail and food consumption was recorded.

During week 4, samples of blood were withdrawn under light general anesthesia and overnight urine samples were collected. Selected parameters for hematology, blood biochemistry and urinalysis were measured.

Pre-dose and in week 4, ophthalmoscopy was performed, and blood samples were collected for assessment of antibodies to AOD9604.

After 4 weeks, animals were euthanized (carbon dioxide asphyxiation). Since the terminal procedures took 2 days to 
complete, the treated animals continued to receive the test substance by daily IV injection until the day before termination.

Killed animals were subjected to a detailed macroscopic organ examination. Masses of all major organs were recorded and tissues were subject to histopathological examination.

From five animals/sex/group, the femur bone marrow was analyzed in the micronucleus assay: The contents of each femur were eluted in a total volume of $10 \mathrm{~mL}$ Hanks' balanced salts solution by aspiration. The resulting cells were pelleted by centrifugation, washed in filtered fetal calf serum and re-suspended in a small volume of fetal calf serum to facilitate smearing on glass microscope slides. Several smears were prepared from each femur and stained using a modified Feulgen staining method which can differentiate micronuclei from mast cell granules.

\section{Six-month rat chronic toxicology study}

This study was carried out by Huntingdon Life Sciences Ltd, Huntingdon, UK, report dated September 2006. Han Wistar rats, at start aged 37 to 41 days (males $100.4 \mathrm{~g}$ to $157.0 \mathrm{~g}$; females $83.30 \mathrm{~g}$ to $117.70 \mathrm{~g}$ ), were housed (four of one sex/ cage) in standard rodent facility conditions enriched by untreated wood blocks at four animals of the same sex/cage.

The cages constituting each group were blocked together by sex and the groups were dispersed in batteries so that possible environmental influences arising from their spatial distribution were equilibrated, as far as was practicable. Additionally, batteries of cages were rotated around the room at weekly intervals to further minimize possible spatial variations. Each animal was assigned a number and was uniquely identified by a tail tattoo. Each cage label was color-coded according to group and was uniquely numbered with cage and study number, as well as the identity of the occupants.

Rats had access to tap water and Rat and Mouse No. 1 Maintenance Diet (Special Diets Services Ltd., England), except the overnight (16 - $17 \mathrm{~h}$ ) before urine and blood collection. After 11-day acclimatization, four groups of rats (12 males, 12 females/group) received 0, 0.5, 20 and 100 mg AOD $9604 / \mathrm{kg} /$ day (vehicle PEG-400) for 26 weeks by oral gavage. Dosing was done in sequence of cage-number within each group, once each day at approximately the same time each day. The dosing volume was $2 \mathrm{~mL} / \mathrm{kg}$.

All formulations were prepared freshly each week by dilution of individual weighings of the test substance within the vehicle, and stored at $4{ }^{\circ} \mathrm{C}$.

After 26 weeks the rats were euthanized (carbon dioxide asphyxiation).

Examinations (omitting micronucleus assays) and statistical evaluations were done as described for the 4-week IV toxicity study with time points of analysis being: 1) body mass: weekly; 2) ophthalmology and blood-sampling for as- sessment of immunogenicity: before treatment and during week 26; 3) urine-sampling for urinalysis and blood-sampling for hematology/blood chemistry: weeks 13 and 26 of treatment; 4) post mortem organ/tissue examinations; bone analysis (pQCT): 26 weeks.

\section{Nine-month cynomolgus monkey chronic toxicology study}

This study was performed by Inveresk Research International Ltd, Tranent, UK, report dated March 2004. On arrival, the 15 - 40 months old cynomolgus monkeys (Macaca fascularis) $(2.1-2.8 \mathrm{~kg})$ were subjected to a detailed veterinary examination.

Study animals were allocated to a dose group and ascribed a computer generated random number, and furthermore allocated to a pen number using further random number sequences. A balanced distribution was achieved taking individual body weights into account. The individual study numbers and the project number were tattooed on the animals' chests (after shaving).

Animals were housed in same-sex-and-dose-groups of three (interim) or four (main study), applying controlled standard primate conditions (gang pens) and an enriched cage environment to promote social interaction, play and exploration. The interim study animals acclimatized to the facility for approximately 5 weeks, the main study animals for 11 weeks before the commencement of treatment. At least once a week, the gang pens were cleaned and shavings replaced as and when necessary.

There was automatic control of temperature and humidity. Target values within the animal rooms were $21^{\circ} \mathrm{C}$ (acceptable limits $17-25^{\circ} \mathrm{C}$ ) for temperature, $55 \%$ (acceptable limits $45-65 \%$ ) for relative humidity and at least 15 air changes per hour. Lighting was controlled to provide a $12 \mathrm{~h}$ light/dark cycle. On a few occasions temperature and humidity were slightly outside the acceptable ranges (as low as 15 ${ }^{\circ} \mathrm{C}$; as high as $26{ }^{\circ} \mathrm{C} / 66 \%$ humidity). These deviations had no overt effect upon any animal and were, therefore considered not to have affected the study outcome.

Each animal was offered free access to drinking water. Also each animal received $200 \mathrm{~g}$ /day of SDS Mazuri Diet (Special Diets Services Limited, England), after completion of dosing on the days of treatment. The feeding regimen was altered on the days when toxicokinetic and clinical pathology blood samples were taken. The monkeys were offered a "Bonio biscuit" after dosing or stressful procedures.

After 5 - 11 weeks of acclimatization, the monkeys received $0,0.5,10$ or $50 \mathrm{mg}$ AOD9604/kg/day in PEG400 (1 $\mathrm{mL} / \mathrm{kg}$, followed by $5 \mathrm{~mL}$ water flush) by oral gavage.

Each dosage group had seven male and seven female monkeys (three males/three females euthanized for interim information after 13 weeks).

During the study, animals were observed at regular in- 
tervals throughout each day for any evidence of ill health or reaction to treatment. Individual body mass was recorded weekly. Blood and urine samples for hematology, blood chemistry and urinalysis were taken before commencement and during weeks $6,13,26$ and 39 using standard procedures ( $7 \mathrm{~mL}$ blood samples from the femoral vein, transferred into plastic tubes containing anticoagulant; urine collection on metabolism trays within individual cages). Week 13 and 39 blood samples were used in an immunogenicity analysis.

Electrocardiogram tracings (using a Cardiofax ECG6851 Nihon Kohden electrocardiogram; Middlesex, UK) were recorded during pre-trial, and (immediately before and approximately $2 \mathrm{~h}$ after dosing) on day 2 and during weeks 6 , 13, 26 and 39. The signals obtained from lead II were evaluated and the interval data (P-R, QRS and Q-T waves) and heart rate were derived.

Ophthalmoscopic examination of both eyes was done under sedation (instillation of $1 \%$ tropicamide; Mydriacy ${ }^{\circledR}$, Alcon Laboratories Inc.), pre-trial and during weeks 6, 13, 26 and 39.

After 39 weeks the animals were euthanized (IV injection of a sodium pentobarbitone overdose, death confirmed by electrocardiogram flatline response) and subjected to a detailed necropsy and macroscopic organ examination. Masses of all major organs were recorded and tissues were subject to microscopic histopathological examination.

Bone analysis, particularly peripheral quantitative computed tomography scanning (pQCT) and histomorphometry, were performed using standard methods.

\section{Statistical analysis of toxicological tests}

All statistical analyses were carried out separately for males and females.

Rat toxicology: The following tests were applied as appropriate: Bartlett's test for analysis of variance (for organs: body mass as covariate); Williams' test/Shirley's non-parametric test for dose-related response; Dunnett's test for nonmonotonic response; Student's $t$-test/Wilcoxon rank sum test for two-group comparisons; Jonkheere-Terpstra test (4-week rat)/Fisher's Exact test (6-month rat) for categorical data. Significance was established at $\mathrm{P}<0.05$ or $\mathrm{P}<0.01$ level.

Monkey toxicology: "F-Max" test for homogeneity of variance (for organs: body mass as covariate); parametric ANOVA for group comparisons, Student's $t$-test for pairwise comparisons against controls; log or square root transformations for heterogeneous variances; Kruskal-Wallis nonparametric ANOVA or chi squared protection for remaining heterogeneous variances.

\section{In vivo pharmacokinetics - analysis of AOD9604 and me- tabolites}

This study was conducted the Victorian Institute of Animal
Science Werribee, Metabolic Pharmaceuticals Ltd Laboratory, Baker Institute, Prahran and CMAX Analytical, Adelaide all located in Australia, report dated March 2004. One pig was dosed with $1.5 \mathrm{mg} / \mathrm{kg}$ AOD9604 by IV bolus administration through a cephalic vein catheter, and another by oral dosing with $2 \mathrm{mg} / \mathrm{kg}$ AOD9604. Blood was collected from the external jugular vein (as well as femoral artery and femoral vein). The plasma was extracted following acetonitrile precipitation for the quantitation of AOD9604 and its peptide degradants by LC/MS/MS (pilot studies in which AOD9604 was spiked into rat plasma identified sequential $\mathrm{N}$-terminal amino acid removal products as the major degradation pathway).

\section{Quantitative rat whole-body radiography}

This study was performed at Covance Laboratories Ltd, Harrogate, UK, report dated August 2004. AOD9604 was labeled with ${ }^{14} \mathrm{C}$ within the cysteines. Male Wistar rats (one animal per time point) received $5 \mathrm{mg} / \mathrm{kg}{ }^{14} \mathrm{C}$-AOD9604 orally by gavage or intravenously by bolus injection via a lateral tail vein. Following deep isoflurane anesthesia, animals were euthanized by freezing (dry-ice in hexane) at the following times: oral consumption: $0.5,1$ and $24 \mathrm{~h}$; IV injection: 5 and $30 \mathrm{~min}$.

A blood sample was taken by cardiac puncture whilst under terminal anesthesia prior to sacrifice, and radioactivity in plasma and cellular fractions was determined by liquid scintillation counting. The frozen carcasses were subject to whole-body autoradiography procedures. Radioactivity concentrations in tissues were quantified from the whole-body autoradiograms, using a validated image analysis system.

\section{Metabolic study with pigs}

This study was performed at the Victorian Institute of Animal Science, Werribee, Monash University, Clayton and CHIRON, Clayton all located in Australia, in September 2000. Six female pigs, receiving standard grower diet, were adjusted to their pens for 14 days. Seven days before onset they were prepared with two cephalic vein catheters, one for AOD9604 injection and one for blood sampling. The pigs received engamycin every 2 days to prevent catheter-induced infection. Three of the pigs received $400 \mu \mathrm{g} / \mathrm{kg}$ AOD9604 via cephalic vein catheter on day 1 and $2,000 \mu \mathrm{g} / \mathrm{kg}$ orally on day 2 . The other 3 pigs received the opposite treatment regime. On day 3 all received 2,000 $\mu \mathrm{g} / \mathrm{kg}$ AOD9604 orally. Blood samples were taken at -120, -60, 0, 1, 2, 3, 4, 5, 6, 7, $8,9,10,12,15,20,30,60,90,120,180$ and 240 min relative to AOD9604 injections or feeding of AOD9604. Blood was collected into heparinized tubes, placed into ice and centrifuged at $2-4{ }^{\circ} \mathrm{C}$ at $4,000 \mathrm{rpm}$ for $5 \mathrm{~min}$ using a T40 Swing Rotor (radius: $100 \mathrm{~mm}$, Jouan, CR-3, France); plasma was immediately removed and placed in dry ice, to be stored at 
Table 2. Cytotoxicity to CHO Cells by Colony Forming Capacity, AOD9604 in Experiment 1

\begin{tabular}{llll}
\hline & Without S-9 $(\mathbf{3}$ h) & & With S-9 (3 h) \\
\hline Dose $\boldsymbol{\mu g} / \mathbf{m L}$ & Relative growth \% & Dose $\boldsymbol{\mu g} / \mathbf{m L}$ & Relative growth \% \\
\hline 0 & 100 & 0 & 100 \\
20 & 91.56 & 20 & 91.81 \\
50 & 92.29 & 50 & 96.58 \\
100 & 85.80 & 100 & 97.88 \\
$200^{1}$ & 108.05 & $200^{1}$ & 108.44 \\
\hline
\end{tabular}

${ }^{1}$ Precipitation observed.

$-80{ }^{\circ} \mathrm{C}$.

Detection of AOD9604 in blood plasma required precipitation of large proteins with $45 \%$ acetonitrile at $-18{ }^{\circ} \mathrm{C}$ as pre-treatment. Following acetonitrile removal by speed-vac, a reverse enzyme-linked immunoassay (EIA) was performed using anti-AOD9604 raised in sheep (detection limit 1 - 2 $\mathrm{ng} / \mathrm{mL}$ ): The samples were incubated in 96-well plates with a 1/3,000 dilution of the AOD9604 antiserum. The left-over antibody was removed in wells coated with biotinylatedAOD9604. The captured antibodies were then detected by using an anti-sheep immunoglobulin horse radish peroxidase conjugate. The amount of peroxidase and hence intensity of color, was indirectly proportional to the amount of AOD9604 present in the samples.

\section{Results}

\section{Bacterial reverse mutation test (Ames test)}

The bacterial reverse mutation test (Ames test) is a measure of mutagenicity of a test substance, in this case AOD9604. All controls gave the expected results, confirming the validity of the test.

In the plate incorporation experiment no strain showed a statistically significant response over the negative control with or without S-9 metabolic activation.

In the pre-incubation experiment, strain WP2 uvrA with S-9, at doses of 200 and 1,000 $\mu \mathrm{g} /$ plate, showed slight, but statistically significant increases in revertants over the negative control. However, there was no complete dose correlation, since $2,000 \mu \mathrm{g} /$ plate did not cause an above-background revertant number.

A second pre-incubation experiment was carried out with this strain using a narrower dose range. No statistically significant increases in revertants over the negative control were seen, the initial finding is not considered to be biologically significant.

For strains TA1535 in the plate incorporation experiment, and WP2 uvrA in the pre-incubation experiment, (both without S-9) an initial run showed unexpected toxicity at 1,000 and $2,000 \mu \mathrm{g} /$ plate as indicated by a reduced bacterial lawn. This left too few doses for estimation of mutagenic potential. The runs were repeated using a wider range of doses. However, the mutagenicity was not repeated.

\section{In vitro chromosome aberration test}

In order to test the potential mutagenic activity of AOD9604 by its ability to cause structural damage to chromosomes, an in vitro cytogenetic test was performed in $\mathrm{CHO}$ cells.

Even at high concentrations, AOD9604 caused no $\mathrm{pH}$ or osmolarity changes. However, at some of the doses, precipitation occurred.

The cytotoxicity examinations did not show any reduction in the capacity to form colonies in a first 3-h treatment experiment. In a second experiment a reduction of colony formation was seen in correlation with dosage and precipitate formation. In the first experiment, there were no statistically significant increases in the number of aberrations following exposure to AOD9604, with or without S-9 (Table 2, 3).

In the second experiment, AOD9604-treated cultures showed a single statistically significant increase in aberrations in the first harvest after 1.5 cell cycles, at $100 \mu \mathrm{g} / \mathrm{mL}$ (without S-9), which was not consistent between duplicate cultures; $200 \mu \mathrm{g} / \mathrm{mL}$ did not show any significant aberrations. Therefore the finding is not considered to be biologically significant.

Interestingly, after the 1.5 cell cycle treatment, an increase in the levels of polyploidy at the first and second harvest times occurred at the two top doses in both replicate cul- 
Table 3. Cytotoxicity to CHO Cells by Colony Forming Capacity, AOD9604 in Experiment 2

\begin{tabular}{llll}
\hline & Without S-9 (1.5 cell cycle) & & With S-9 (3 h) \\
\hline Dose $\boldsymbol{\mu g} / \mathbf{m L}$ & Relative growth \% & Dose $\boldsymbol{\mu g} / \mathbf{m L}$ & Relative growth \% \\
\hline 0 & 100 & 0 & 100 \\
20 & 162.72 & $20^{1}$ & 62.88 \\
100 & 84.90 & $100^{1}$ & 48.79 \\
200 & 70.29 & $200^{1}$ & 46.54 \\
$500^{1}$ & 3.55 & - & - \\
$1,000^{1}$ & 0.00 & - & - \\
\hline
\end{tabular}

${ }^{1}$ Precipitation observed.

tures and at both harvest times without metabolic activation. However, polyploidy induction was absent in the mitomycin $\mathrm{C}$ positive control, and was not present with metabolic activation.

\section{Four-week IV toxicity study in rats}

To exclude possible signs of toxicity or genotoxic effects, a 4-week IV toxicity study with an incorporated bone micronucleus assay was performed. Rats were intravenously injected with AOD9604 for 4 weeks with dosages up of 0.1 ,
1.0 or $10 \mathrm{mg} / \mathrm{kg}$. There were no treatment-related deaths, clinical signs, or local effects at the injection site. There were no treatment-related effects on food consumption, however, interestingly, group mean body mass gain of females receiving 1.0 and $10.0 \mathrm{mg} / \mathrm{kg} /$ day AOD9604 was significantly reduced over the 4 weeks treatment, with the effect starting in week 1. Group mean body mass gain of males receiving $10.0 \mathrm{mg} / \mathrm{kg} /$ day AOD9604 was reduced from weeks 2 to 4 , however did not reach significance.

There were no treatment-related findings, regarding ophthalmology, hematology, biochemistry and urinalysis, or

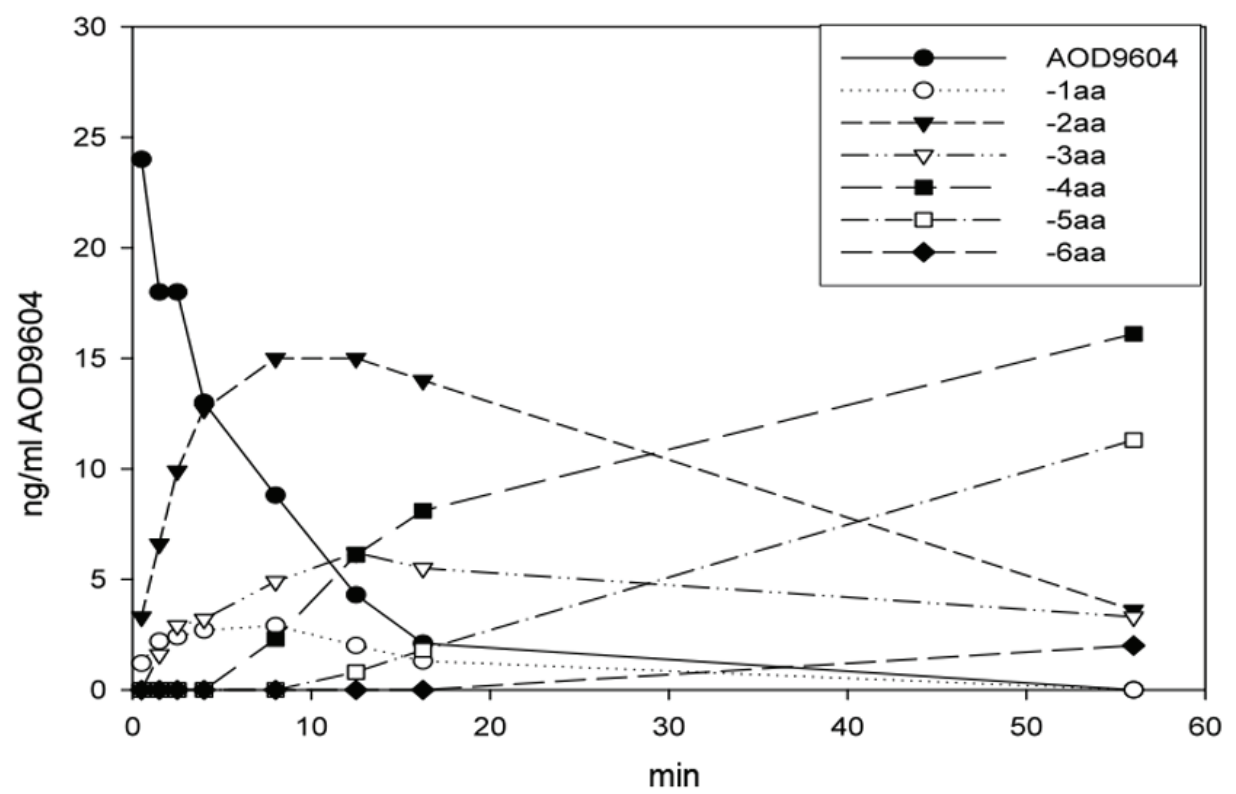

Figure 1. Degradation of AOD9604 in rat plasma in vitro at room temperature. After 56 min, the peptide is completely eliminated. The half-life is approximately $4 \mathrm{~min}$. The appearance of AOD9604 amino-terminal truncated fragments (-xaa) is demonstrated. 

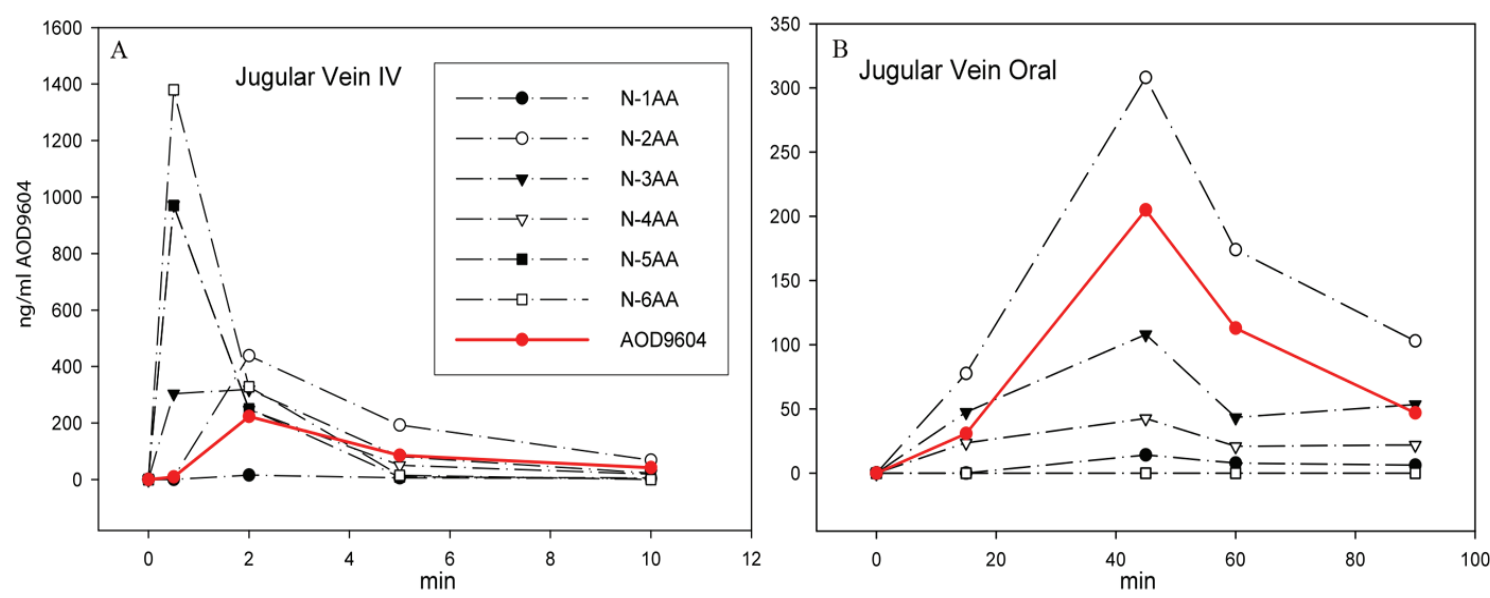

Figure 2. After IV (A) or oral (B) application of AOD9604 to two different pigs, the extracted plasma from jugular vein blood was analyzed by MS to quantitate AOD9604 and its degradants. The concentration of AOD9604 and its degradants (lacking 1 - 6 amino acids) in the plasma at different sampling times is indicated.

macroscopic pathology. There were also no deviations in the organ masses with correlation in dosage, or other findings, except that the males receiving $10 \mathrm{mg} / \mathrm{kg} /$ day AOD9604 had significantly reduced thymus masses. Also the microscopic organ examination did not yield any significant results, though an increased incidence of decreased thymic cortical width in both sexes receiving $10 \mathrm{mg} / \mathrm{kg} /$ day was noted but did not reach significance. This characteristic was also found in the other groups, including the control groups, but at lower frequency.

No-anti-AOD9604 antibodies were detected in rat serum following 4 weeks of treatment.

\section{Bone-marrow micronucleus test}

Incorporated in the design of the rat toxicity IV study was a bone micronucleus assay. After 4 weeks of IV treatment with AOD9604 a slight increase in micronucleus formation was observed for 0.1 and $10 \mathrm{mg} / \mathrm{kg}$, but not for the medium dosage group $1 \mathrm{mg} / \mathrm{kg}$. Due to the lacking dosage relationship, this could not be interpreted as evidence that AOD9604 caused chromosomal damage. There was no evidence of cellular toxicity in the bone marrow and no substantial decrease in the proportion of immature erythrocytes.

\section{Degradation pharmacokinetics}

When AOD9604 was added to fresh rat blood at room temperature, $75-80 \%$ of the AOD9604 was lost after one hour, whereas there were no significant losses, if the blood was heparinized, immediately chilled and processed.

Similarly, AOD9604 spiked into rat plasma at room temperature degraded rapidly by amino-terminal truncation of the peptide in a cascade fashion, as can be shown by MS peptide analysis (Fig. 1). The serum half-life was ap- proximately 4 min, with intact AOD9604 undetectable 56 min after spiking. No carboxyl-terminal truncated forms or amino-terminal truncated forms beyond the disulfide bridge were detected. AOD9604 degraded in vivo in IV dosed pigs, AOD9604 and its peptide degradants appeared rapidly. The -2aa (minus 2 amino acids) and -3 aa were the principal fragments observed in vivo (Fig. 2). Both of these fragments are known to have some (reduced) in vitro anti-lipogenic activity. Orally, the kinetics is slower, but the same degradants are observed.

\section{Rat whole-body radiography}

The distribution of ${ }^{14} \mathrm{C}$-AOD9604 in rats following a single oral or single IV administration was examined. Whole-body radiography $5 \mathrm{~min}$ after IV administration produced label throughout the body, with the exception of the CNS (Fig. 3) (Table 4). Principal sites of localization were the pancreas, the pineal body, the thyroid, the liver and the kidney cortex.

When ${ }^{14} \mathrm{C}$-AOD9604 was administered to rats by oral gavage, radiolabel was maximally detected in the tissues of the dosed rats 30 min after administration (Fig. 4) (Table 4). Principal sites of localization were similar to the IV results. Estimates from radioactivity distribution indicate $40 \%$ oral availability.

After $24 \mathrm{~h}$ the label was more evenly distributed to all tissues in the body, except for the CNS.

The oral absorption (potentially through the stomach) in rats was also confirmed by detection of AOD9604 in rat plasma 15 min after dosing (data not shown).

\section{Pharmacokinetic study with pigs}

In pigs, IV administration of $400 \mu \mathrm{g} / \mathrm{kg}(0.4 \mu \mathrm{g} / \mathrm{g}) \mathrm{AOD} 9604$ leads to a maximum plasma concentration of $1,945 \mathrm{ng} / \mathrm{mL}$ 

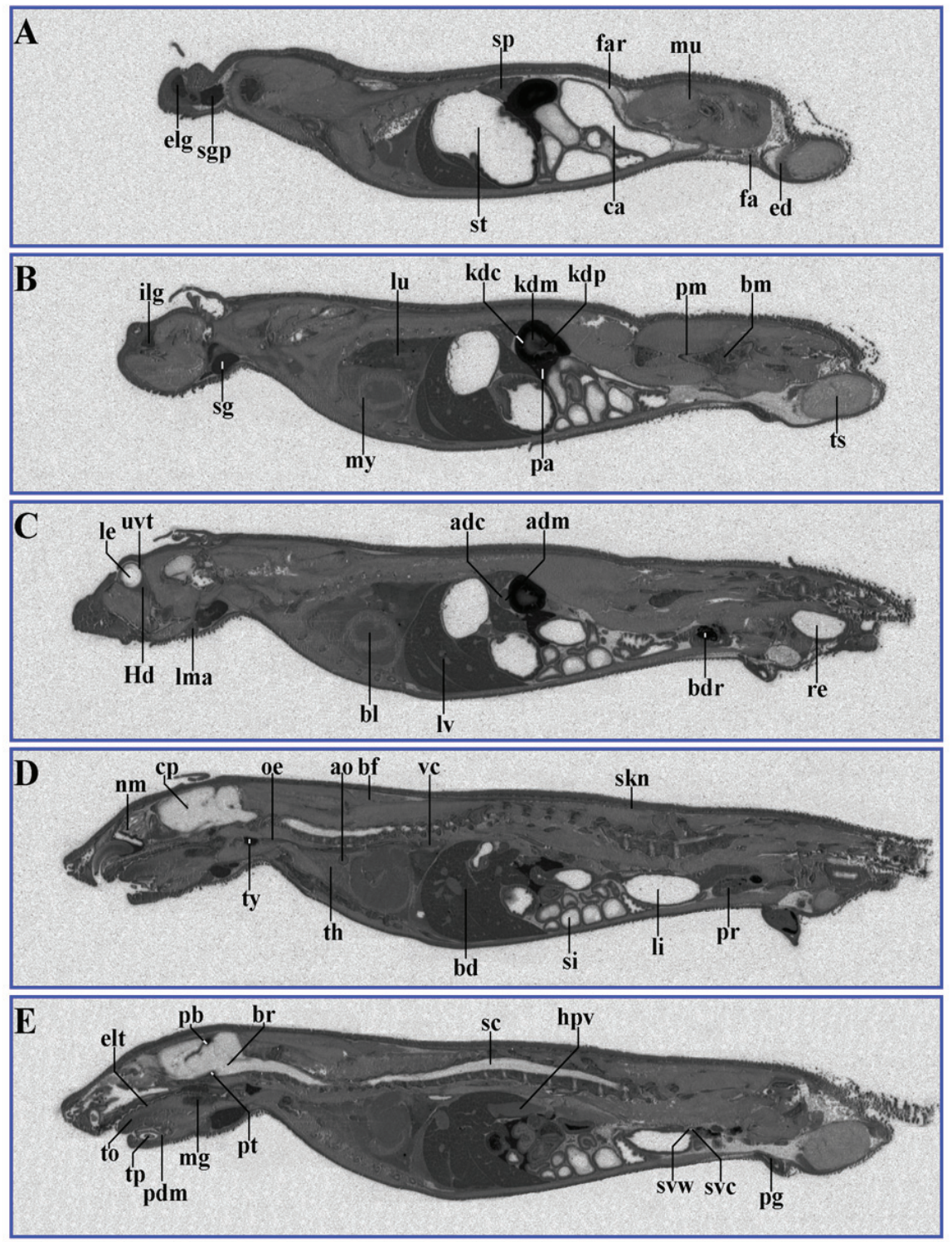

Figure $3 .{ }^{14} \mathrm{C}-\mathrm{AOD} 9604(5 \mathrm{mg} / \mathrm{kg})$, labeled within the cysteines, was administered IV to rats. The animals were subsequently sectioned and subjected to quantitative whole-body radiography. (A-E): serial sections, 5 min after IV administration (slight digital brightness modification of image). Principal sites of localization are the pancreas, pineal body, thyroid, kidney cortex and liver.

$(1.9 \mu \mathrm{g} / \mathrm{mL})$ after 2 min (Fig. 5A). Accordingly, most, if not all of the injected substance could be detected in the pig plasma after $2 \mathrm{~min}$, distributed throughout the major blood vessels only.

Following IV injection in pigs, there was a rapid clearance of AOD9604 from the bloodstream. AOD9604 had a very short half-life of only approximately $3 \mathrm{~min}$ after IV injection. At 12 min past IV injection, almost all of the AOD9604 had cleared from the blood plasma, resulting in a relatively small AUC.

When the pigs received AOD9604 orally at $2 \mathrm{mg} / \mathrm{kg}$ (2 $\mu \mathrm{g} / \mathrm{g}$ ) (Fig. 5B), there was, a prolonged entry into the bloodstream with a lower maximal plasma concentration as com- pared to the $\mathrm{C}_{\text {max }}$ after IV injection, although five-fold more AOD9604 was applied orally. Individual and day-to-day variability could be observed (error bars).

Interestingly the oral AUC was 8.5 times higher than under IV injection. In an oral repeat dosing experiment with the same pigs one day later, the general kinetics could be confirmed, with an AUC of $83,871.6(\mathrm{SD} \pm 5,479.6) \mathrm{ng} / \mathrm{mL} /$ min (6.6 times higher than IV)

\section{Six-month rat chronic toxicology study}

A 6-month rat oral gavage chronic toxicology study was conducted to evaluate the long-term tolerability and safety of 
Table 4. Abbreviations

\begin{tabular}{|c|c|}
\hline Adrenal cortex & adc \\
\hline Adrenal medulla & $\mathrm{adm}$ \\
\hline Aorta & ao \\
\hline Bile ducts & bd \\
\hline Bladder & bdr \\
\hline Blood & bl \\
\hline Bone marrow & $\mathrm{bm}$ \\
\hline Brain & br \\
\hline Brown fat & bf \\
\hline Bulbo-urethral gland & bug \\
\hline Caecum & $\mathrm{ca}$ \\
\hline Choroid plexus & cp \\
\hline Epididymis & ed \\
\hline Epithelial lining (tongue) & elt \\
\hline Exorbital lachrymal gland & elg \\
\hline Harderian gland & $\mathrm{Hd}$ \\
\hline Hepatic portal vein & hpv \\
\hline Intra-orbital lachrymal gland & ilg \\
\hline Kidney cortex & $\mathrm{kdc}$ \\
\hline Kidney medulla & $\mathrm{kdm}$ \\
\hline Kidney pyramid & kdp \\
\hline Large intestine & li \\
\hline Lens & le \\
\hline Liver & lv \\
\hline Lung & lu \\
\hline Mandibular lymph nodes & $\operatorname{lma}$ \\
\hline Mucus gland & $\mathrm{mg}$ \\
\hline Muscle & $\mathrm{mu}$ \\
\hline Myocardium & my \\
\hline Nasal mucosa & $\mathrm{nm}$ \\
\hline Non-pigmented skin & skn \\
\hline Oesophagus & oe \\
\hline Pancreas & pa \\
\hline Parotid salivary gland & sgp \\
\hline Peridontal membrane & pdm \\
\hline Periosteum & $\mathrm{pm}$ \\
\hline Peri-renal fat & far \\
\hline Pineal body & $\mathrm{pb}$ \\
\hline Pituitary & $\mathrm{pt}$ \\
\hline Preputial gland & pg \\
\hline Prostate & $\mathrm{pr}$ \\
\hline Rectum & re \\
\hline Salivary glands & sg \\
\hline Seminal vesicle contents & svc \\
\hline Seminal vesicle wall & svw \\
\hline Small intestine & si \\
\hline Spinal cord & $\mathrm{sc}$ \\
\hline Spleen & $\mathrm{sp}$ \\
\hline Stomach & st \\
\hline Testis & ts \\
\hline Thymus & th \\
\hline Thyroid & ty \\
\hline Tongue & to \\
\hline Tooth pulp & tp \\
\hline Uveal tract & uvt \\
\hline Vena cava & $\mathrm{vc}$ \\
\hline White fat & $\mathrm{fa}$ \\
\hline
\end{tabular}

AOD9604. There were no unscheduled deaths and no clinical signs of toxicological significance.

A trend for lower body mass gain was noted for all females receiving AOD9604, along with slightly lower food consumption for the 0.5 and $20 \mathrm{mg} / \mathrm{kg} /$ day females.

There were no treatment-related differences from the control group regarding urine, organ masses, macropathology, ophthalmology, histopathology or bone characteristics. No significant concentrations of anti-AOD9604 antibodies were detected.

In week 13, a statistically lower lymphocyte count was noted for females receiving $0.5,20$ or $100 \mathrm{mg} / \mathrm{kg} /$ day, with $20 \mathrm{mg} / \mathrm{kg}$ /day exhibiting the largest difference. In week 26, a similar trend was observed.

Some differences regarding blood chemistry were noted: In week 13 , males receiving $0.5,20$ or $100 \mathrm{mg} / \mathrm{kg} /$ day had significantly higher urea concentrations, without a dosage relationship. In week 26 the same effect was only a trend. Slightly but significantly higher creatinine and triglyceride levels were noted in weeks 13 and 26 for males receiving $100 \mathrm{mg} / \mathrm{kg} /$ day. In week 13, males receiving $100 \mathrm{mg} / \mathrm{kg} /$ day and females receiving 20 or $100 \mathrm{mg} / \mathrm{kg} /$ day had significantly lower osteocalcin levels. In week 26 significantly higher osteocalcin levels were observed for females receiving 20 or $100 \mathrm{mg} / \mathrm{kg} /$ day.

Altogether, the lack of dosage relationships and/or the absence of any corroborative pathology suggest that these deviations were of no toxicological importance.

\section{Nine-month cynomolgus monkey chronic toxicology study}

A 9-month oral gavage chronic toxicology study in cynomolgus monkeys evaluated the long-term tolerability and safety of AOD 9604 (up to $50 \mathrm{mg} / \mathrm{kg} /$ day) in non-rodents.

No significant body mass differences, ophthalmic or electrocardiogram findings, treatment-related hematological or biochemical findings, or changes in urinary composition were observed. There were no necropsy or histological findings associated with the treatment, also organ masses and bone densitometry were unaffected by the treatment. However, besides some minor findings without dosage relationship, the following deviations were observed: after 39 weeks, all treated male (but not female) groups had statistically lower covariate liver masses and lower liver glycogen levels compared to controls. Minimal or slight periportal vacuolation was present in the liver of a control female, a female given $0.5 \mathrm{mg} / \mathrm{kg} / \mathrm{day}$, two males given $10 \mathrm{mg} / \mathrm{kg} /$ day and all females given $50 \mathrm{mg} / \mathrm{kg} /$ day.

Altogether, the differences regarding liver mass or vacuolation were minor, showed no dosage relationship, and therefore cannot be attributed with certainty to AOD9604 treatment.

No significant levels of anti-AOD9604 antibodies were 

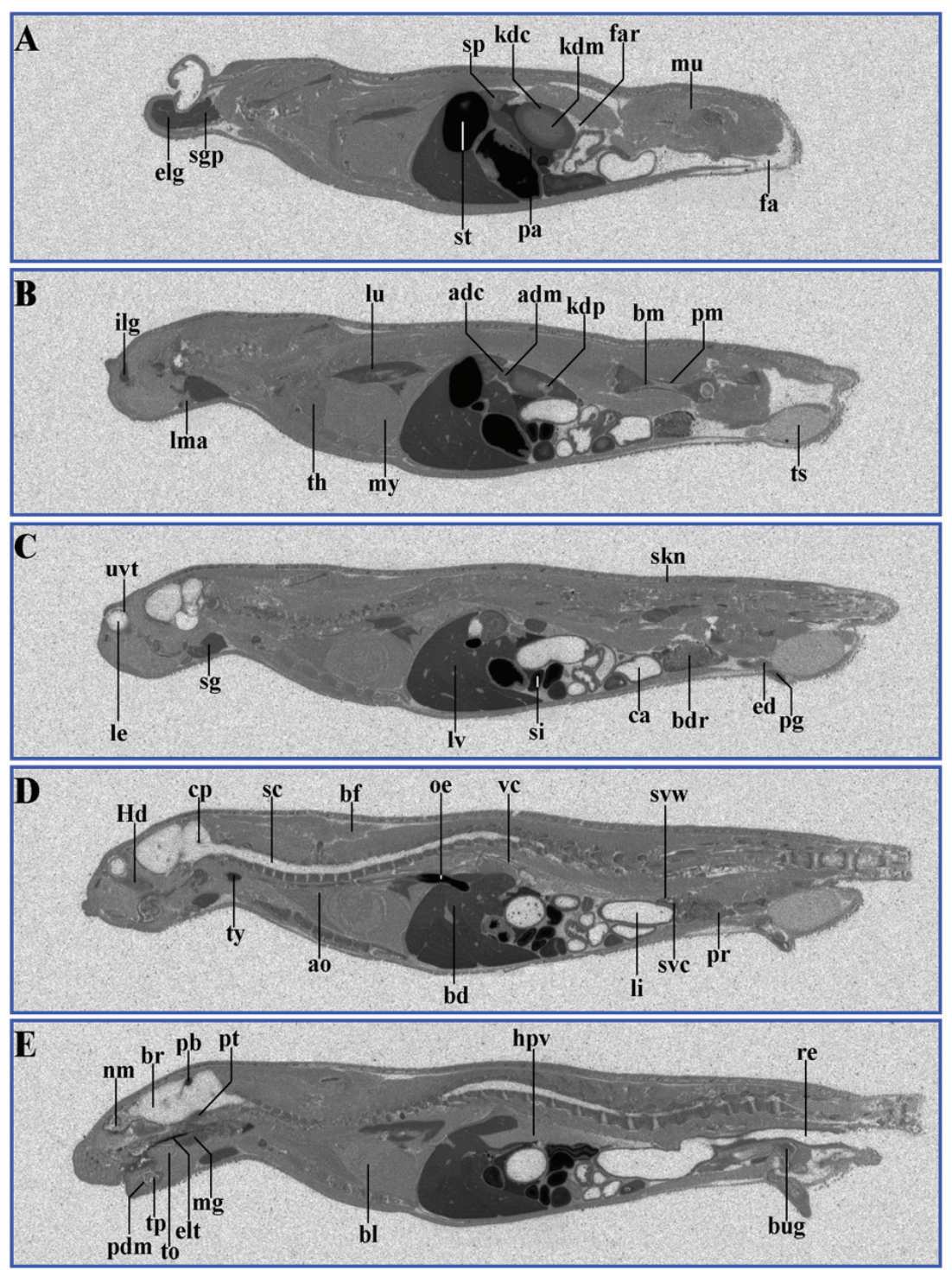

Figure 4. ${ }^{14} \mathrm{C}-A O D 9604(5 \mathrm{mg} / \mathrm{kg})$, labeled within the cysteines, was administered by oral gavage to rats. The animals were subsequently sectioned and subjected to quantitative whole-body radiography. (A-E): serial sections, 30 min after oral gavage administration. Principal sites of localization are pancreas, pineal body, thyroid, kidney cortex and liver and the upper gastrointestinal tract (stomach). It should be noted that later time points (for example, $24 \mathrm{~h}$ ) are likely to represent degradants, so the data is not shown.

detected after 13 or 39 weeks.

\section{Discussion}

A conventional Ames test showed no significant mutation rate increase for AOD9604 up to 2,000 $\mu \mathrm{g} / \mathrm{plate}$. In the CHO-cell chromosome aberration assay AOD9604 was not clastogenic, but the observed dose-related growth inhibition and the increase of polyploidy could indicate an interfering effect on cell cycling at very high concentrations. AOD9604 did not induce a consistently increased number of micronu- clei. Altogether it can be concluded that there are no genotoxic concerns regarding AOD9604.

After oral administration, MS peptide analysis and EIA methods prove the appearance of AOD9604 (and its degradation fragments) in pig plasma. Thus, AOD9604 is bioavailable orally. Due to the nature of the digestion process, absorption from the digestive tract is more protracted than after IV injection.

The slightly higher AUC after oral administration (Fig. 2B, 5B) could imply a higher plasma half-life after absorption from the digestive tract, however experimental error (error bars), (Fig. 5B) is the most likely explanation. Hypotheti- 

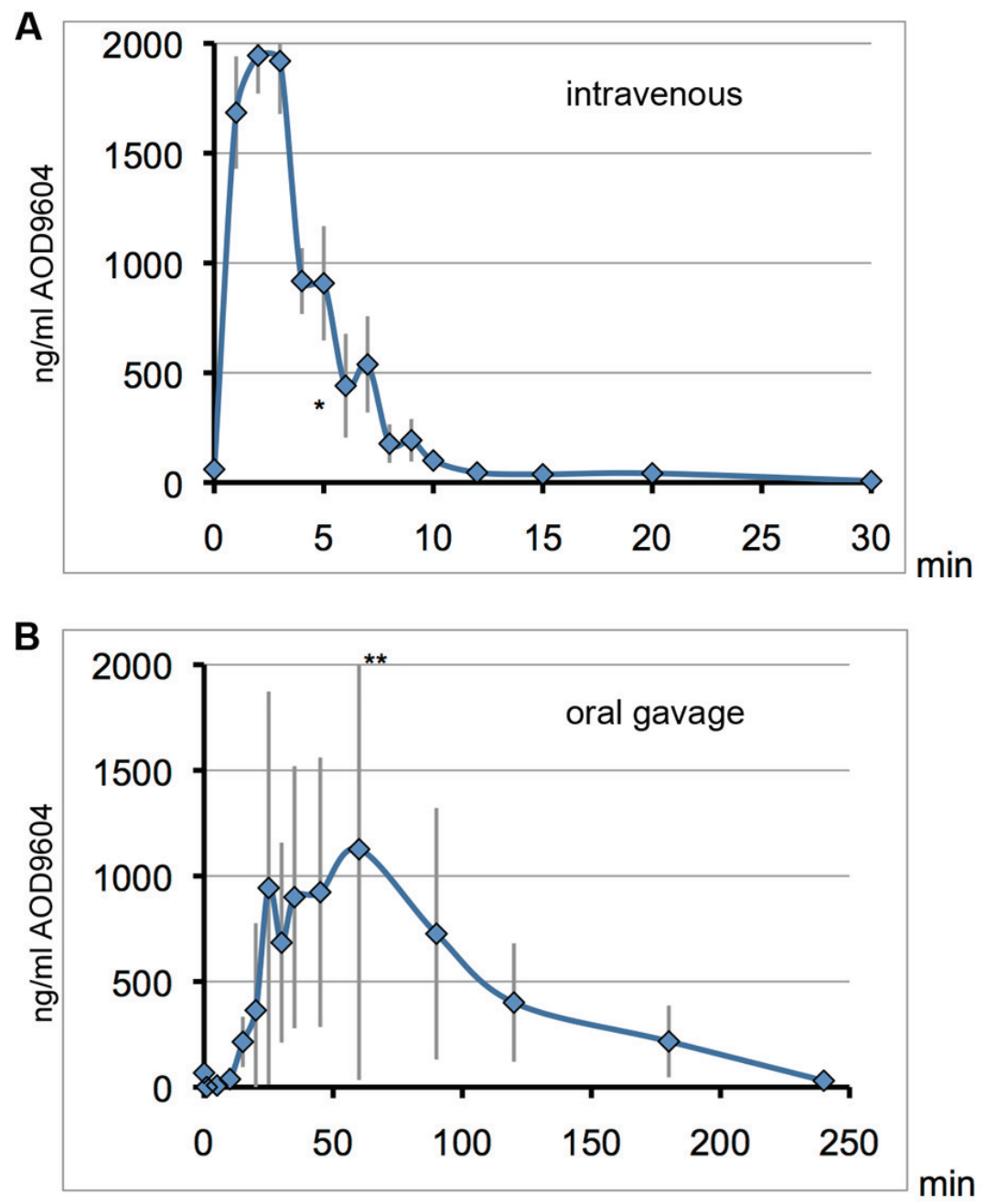

Figure 5. On consecutive days, the same 6 pigs received AOD9604 intravenously (A) or with oral gavage (B). Blood serum was analyzed for AOD9604 levels by immunoassay and concentrations are plotted against the sampling time. Error bars for the standard deviation are depicted in grey. *data point of one pig omitted due to an extremely high value indicating a technical error. ${ }^{* *}$ top error bar slightly cut off. (A) IV injection (400 $\mu \mathrm{g} / \mathrm{kg}$ AOD9604): $\mathrm{T}_{1 / 2}=3 \mathrm{~min}, \mathrm{~T}_{\max }=2 \mathrm{~min}, \mathrm{C}_{\max }=1,944 \mu \mathrm{g} / \mathrm{mL}, \mathrm{AUC}=$ $12,743.42(\mathrm{SD} \pm 625.3) \mathrm{ng} / \mathrm{mL} / \mathrm{min}$; (B) Oral gavage $\left(2,000 \mu \mathrm{g} / \mathrm{kg}\right.$ AOD9604): $\mathrm{C}_{\max }=1,127 \mu \mathrm{g} / \mathrm{mL}, \mathrm{T}_{\max }=60 \mathrm{~min}, A U \mathrm{C}=108,630$ $(\mathrm{SD} \pm 32,654.3) \mathrm{ng} / \mathrm{mL} / \mathrm{min}$.

cally the effect could be explained by AOD9604 binding to a protective protein during digestive uptake.

Regular hGH has a plasma half life of 21 min [39]. Expectedly, AOD9604 as fragment of hGH, has a briefer halflife (3 min; IV injection).

The rapid clearance of AOD9604 could be due to enzymatic degradation: in vitro and in vivo rapid sequential removal of amino acids from AOD9604 is observed (Fig. $1,2)$. In vivo, unspecific and specific cellular absorption of AOD9604 or degradation metabolites may additionally take place. This is supported by the radiolabeling experiment, where all non-CNS tissues and especially certain organs like the pineal body and thyroid exhibited elevated AOD9604 levels (Fig. 3, 4).

Rats, injected IV with AOD9604 experienced a reduced body mass gain, not only in this study, but also in previous 14 and 28 day IV rat toxicology studies, demonstrating metabolic action, consistent with its known activity on body weight. As expected, the effects were slight in these non-obese animals: in previous experiments, the lipolytic effects of various C-terminal hGH fragments were observed in obese but not lean animal models.

The absence of antibodies to AOD9604 in all animal experiments indicates that the test article is not immunogenic, thus there should be no allergy concerns.

The no-observed-adverse-effect level (NOAEL) for rats under chronic conditions is at least equal to the highest applied dosage of $100 \mathrm{mg} / \mathrm{kg} /$ day. For cynomolgus monkeys, chronic dose levels up to $50 \mathrm{mg} / \mathrm{kg} /$ day can be considered as NOAEL. 


\section{Acknowledgement}

We acknowledge the following parties: 1) Professor Frank $\mathrm{Ng}$ and co-workers at Monash University, Clayton Australia for their original discovery of AOD9604 and its fat metabolic properties; 2) the staff of Metabolic Pharmaceuticals Ltd for their work in progressing the non-human and human clinical testing of AOD9604; 3 ) the collaborating companies and institutions named in this report together with their staff for the high quality of research work undertaken on behalf of Metabolic Pharmaceuticals Ltd. Also, we thank Dr Andrew Gearing and Ms Mareco Hutchinson for reviewing the draft manuscript and assisting with editing.

\section{Declaration of Interest}

David Kenley is the Chief Executive Officer of Metabolic Pharmaceutical Pty Ltd. Mr Kenley has stock representing $7.3 \%$ of Calzada Limited, the $100 \%$ parent company of Metabolic Pharmaceuticals Pty Ltd.

\section{Grant Support}

These studies were funded by Metabolic Pharmaceuticals Ltd and related human studies were supported by an Australian Commonwealth Government R\&D Start Program Grant from the Industry Research and Development Board.

\section{References}

1. Khan A, Raza S, Khan Y, Aksoy T, Khan M, Weinberger Y, Goldman J. Current updates in the medical management of obesity. Recent Pat Endocr Metab Immune Drug Discov. 2012;6(2):117-128.

2. Ogru E, Wilson JC, Heffernan M, Jiang WJ, Chalmers DK, Libinaki R, Ng F. The conformational and biological analysis of a cyclic anti-obesity peptide from the Cterminal domain of human growth hormone. J Pept Res. 2000;56(6):388-397.

3. Kreitschmann-Andermahr I, Suarez P, Jennings R, Evers N, Brabant G. GH/IGF-I regulation in obesity--mechanisms and practical consequences in children and adults. Horm Res Paediatr. 2010;73(3):153-160.

4. Baumann G. Growth hormone heterogeneity in human pituitary and plasma. Horm Res. 1999;51(Suppl 1):2-6.

5. Thoner MO, Vance ML, Laws ER, Horvath E and Kovacs K, 1998. In: Wilson JD, OFoster DW, Kronenberg HM, Larsen PR (eds). Williams Textbook of Endokrinology, vol 9th ed. W.B. Saunders Company, Philadelphia, pp 256-263.

6. Vijayakumar A, Novosyadlyy R, Wu Y, Yakar S, Le-
Roith D. Biological effects of growth hormone on carbohydrate and lipid metabolism. Growth Horm IGF Res. 2010;20(1):1-7.

7. Ho KK, O'Sullivan AJ, Hoffman DM. Metabolic actions of growth hormone in man. Endocr J. 1996;43(Suppl):S57-63.

8. Frohman LA, MacGillivray MH, Aceto T, Jr. Acute effects of human growth hormone on insulin secretion and glucose utilization in normal and growth hormone deficient subjects. J Clin Endocrinol Metab. 1967;27(4):561567.

9. Raben MS, Hollenberg CH. Effect of growth hormone on plasma fatty acids. J Clin Invest. 1959;38(3):484488.

10. Davidson MB. Effect of growth hormone on carbohydrate and lipid metabolism. Endocr Rev. 1987;8(2):115131.

11. Gravholt CH, Schmitz O, Simonsen L, Bulow J, Christiansen JS, Moller N. Effects of a physiological GH pulse on interstitial glycerol in abdominal and femoral adipose tissue. Am J Physiol. 1999;277(5 Pt 1):E848854.

12. Rodriguez-Arnao J, Jabbar A, Fulcher K, Besser GM, Ross RJ. Effects of growth hormone replacement on physical performance and body composition in GH deficient adults. Clin Endocrinol (Oxf). 1999;51(1):53-60.

13. Johannsson G, Bengtsson BA. Growth hormone and the metabolic syndrome. J Endocrinol Invest. 1999;22(5 Suppl):41-46.

14. Takahashi S, Satozawa N. The 20-kD human growth hormone reduces body fat by increasing lipolysis and decreasing lipoprotein lipase activity. Horm Res. 2002;58(4):157-164.

15. Bredella MA, Lin E, Brick DJ, Gerweck AV, Harrington LM, Torriani M, Thomas BJ, et al. Effects of GH in women with abdominal adiposity: a 6-month randomized, double-blind, placebo-controlled trial. Eur J Endocrinol. 2012;166(4):601-611.

16. Mekala KC, Tritos NA. Effects of recombinant human growth hormone therapy in obesity in adults: a meta analysis. J Clin Endocrinol Metab. 2009;94(1):130-137.

17. Rosenbaum M, Gertner JM, Leibel RL. Effects of systemic growth hormone $(\mathrm{GH})$ administration on regional adipose tissue distribution and metabolism in GH-deficient children. J Clin Endocrinol Metab. 1989;69(6):1274-1281.

18. Franco C, Andersson B, Lonn L, Bengtsson BA, Svensson J, Johannsson G. Growth hormone reduces inflammation in postmenopausal women with abdominal obesity: a 12-month, randomized, placebo-controlled trial. J Clin Endocrinol Metab. 2007;92(7):2644-2647.

19. Bickel M, Zangos S, Lutz T, Eisen J, Knecht G, Goebel FD, Crespi CM, et al. Long-term effect on body composition and metabolic parameters after treatment with 
recombinant human growth hormone (r-hGH) in HIV-1 infected patients with lipodystrophy. Scand J Infect Dis. 2008;40(1):36-39.

20. Bickel M, Zangos S, Jacobi V, Lutz T, Knecht G, Goebel F, Staszewski S, et al. A randomized, open-label study to compare the effects of two different doses of recombinant human growth hormone on fat reduction and fasting metabolic parameters in HIV-1-infected patients with lipodystrophy. HIV Med. 2006;7(6):397-403.

21. Child CJ, Zimmermann AG, Scott RS, Cutler GB, Jr., Battelino T, Blum WF. Prevalence and incidence of diabetes mellitus in GH-treated children and adolescents: analysis from the GeNeSIS observational research program. J Clin Endocrinol Metab. 2011;96(6):E10251034.

22. Cameron CM, Kostyo JL, Adamafio NA, Dunbar JC. Metabolic basis for the diabetogenic action of growth hormone in the obese (ob/ob) mouse. Endocrinology. 1987;120(4):1568-1575.

23. Scacchi M, Pincelli AI, Cavagnini F. Growth hormone in obesity. Int J Obes Relat Metab Disord. 1999;23(3):260271.

24. Climmons DR UL,1986. Growth hormone as a potential adjunctive therapy for weight loss. In: LE U (ed). Human growth Hormone Progress and Challenges. Marcel Dekker Inc, New York, pp 207-217.

25. Takahashi S, Shiga Y, Satozawa N, Hayakawa M. Diabetogenic activity of $20 \mathrm{kDa}$ human growth hormone $(20 \mathrm{~K}-\mathrm{hGH})$ and $22 \mathrm{~K}-\mathrm{hGH}$ in rats. Growth Horm IGF Res. 2001;11(2):110-116.

26. Hayakawa M, Shimazaki Y, Tsushima T, Kato Y, Takano K, Chihara K, Shimatsu A, et al. Metabolic effects of 20 -kilodalton human growth hormone $(20 \mathrm{~K}-\mathrm{hGH})$ for adults with growth hormone deficiency: results of an exploratory uncontrolled multicenter clinical trial of $20 \mathrm{~K}$ hGH. J Clin Endocrinol Metab. 2004;89(4):1562-1571.

27. Ng FM, Bornstein J, Welker C, Zimmet PZ, Taft P. Insulin potentiating action of synthetic peptides relating to the amino terminal sequence of human growth hormone. Diabetes. 1974;23(12):943-949.

28. Lim N, Ng FM, Wu ZM, Ede N, Hearn MT. Hypoglycemic action of a novel constrained analog of human growth hormone-(6-13). Endocrinology. 1992;131(2):835-840.

29. Mondon CE, Reaven GM, Ling N, Lewis UJ, Frigeri LG. Amino-terminal peptide of growth hormone enhances insulin action in normal rats. Endocrinology.
1988;123(2):827-833.

30. Jeoung DI, Allen DL, Guller S, Yen V, Sonenberg M. Mitogenic and receptor activities of human growth hormone 108-129. J Biol Chem. 1993;268(30):2252022524.

31. Ng FM, Sun J, Sharma L, Libinaka R, Jiang WJ, Gianello R. Metabolic studies of a synthetic lipolytic domain (AOD9604) of human growth hormone. Horm Res. 2000;53(6):274-278.

32. $\mathrm{Wu} \mathrm{Z}, \mathrm{Ng}$ FM. Antilipogenic action of synthetic Cterminal sequence 177-191 of human growth hormone. Biochem Mol Biol Int. 1993;30(1):187-196.

33. Natera SH, Jiang WJ, Ng FM. Reduction of cumulative body weight gain and adipose tissue mass in obese mice: response to chronic treatment with synthetic hGH 177191 peptide. Biochem Mol Biol Int. 1994;33(5):10111021.

34. Heffernan MA, Jiang WJ, Thorburn AW, Ng FM. Effects of oral administration of a synthetic fragment of human growth hormone on lipid metabolism. Am J Physiol Endocrinol Metab. 2000;279(3):E501-507.

35. Ng FM, Jiang WJ, Gianello R, Pitt S, Roupas P. Molecular and cellular actions of a structural domain of human growth hormone (AOD9401) on lipid metabolism in Zucker fatty rats. J Mol Endocrinol. 2000;25(3):287298.

36. Heffernan MA, Thorburn AW, Fam B, Summers R, Conway-Campbell B, Waters MJ, Ng FM. Increase of fat oxidation and weight loss in obese mice caused by chronic treatment with human growth hormone or a modified C-terminal fragment. Int J Obes Relat Metab Disord. 2001;25(10):1442-1449.

37. Heffernan M, Summers RJ, Thorburn A, Ogru E, Gianello R, Jiang WJ, Ng FM. The effects of human GH and its lipolytic fragment (AOD9604) on lipid metabolism following chronic treatment in obese mice and beta(3)-AR knock-out mice. Endocrinology. 2001;142(12):51825189.

38. Stier H, Vos E, Kenley D. Safety and Tolerability of the Hexadecapeptide AOD9604 in Humans. J Endocrinol Metab. 2013;3(1-2):7-15.

39. Langendonk JG, Meinders AE, Burggraaf J, Frolich M, Roelen CA, Schoemaker RC, Cohen AF, et al. Influence of obesity and body fat distribution on growth hormone kinetics in humans. Am J Physiol. 1999;277(5 Pt 1):E824-829. 